\title{
Projeto Horta Viva na Escola
}

\author{
Project live garden in the school
}

Jaqueline Rambo Anschau ${ }^{1}$, Bianca Motta Dolianitis², Gabriel Cogo Pagliarin ${ }^{3}$, Janessa Aline Zappe ${ }^{4}$, Rosana Santos de Moraes $^{5}$ e Viviane Dal-Souto Frescura ${ }^{6}$
${ }^{1}$ Laboratório de processos Biológicos, Universidade Federal de Santa Maria - Campus Cachoeira do Sul, Brasil jaquirambo@hotmail.com
2,3,4,5,6 Universidade Federal de Santa Maria - Campus Cachoeira do Sul, Brasil

biancadolianitis@hotmail.com; viviane.frescura@ufsm.br; jalinez@hotmail.com; rosana-moraes95@hotmail.com; viviane.frescura@ufsm.br

\section{Resumo}

A presença de hortas nas escolas é cada vez mais incomum devido à grande facilidade e praticidade do uso de produtos industrializados para alimentação dos alunos, o que acarreta na desvalorização dos alimentos naturais e no desinteresse crescente das crianças por usar vegetais na alimentação. No entanto, o uso de vegetais é de grande importância para o desenvolvimento nutricional das crianças que se encontram em fase de crescimento. Portanto, com o presente trabalho, objetivou-se implantar hortas em escolas de Educação Infantil, Ensino Fundamental e Ensino Médio. Durante o ano de 2017 o projeto foi desenvolvido em quatro escolas, em diferentes localidades, em Novo Cabrais, Cachoeira do Sul e Santiago, no estado do Rio Grande do Sul. Foi realizada uma palestra informativa tratando de informações sobre o preparo das hortas e importância do consumo de alimentos saudáveis. Ao final do desenvolvimento do projeto, foi possivel observar o quanto foi satisfatório e relevante para cada um dos alunos, independente da idade, ajudar no plantio das mudas, poder observar o crescimento e desenvolvimento de cada planta.

Palavras-chave: Hortas escolares; Alimentação saudável; Educação ambiental

\section{Abstract}

The presence of vegetable gardens in schools is increasingly uncommon due to the great ease and practicality of the use of industrialized products to feed students, which causes the devaluation of natural foods and the growing disinterest of children for using vegetables in food. However, the use of vegetables is of great importance for the nutritional development of children who are growing. Therefore, with the present work, the objective was to implement gardens in schools of Early Childhood, Elementar School and High School. During the year 2017 the project was developed in four schools in different locations in Novo Cabrais, Cachoeira do Sul and Santiago, in the state of Rio Grande do Sul. An informative lecture was held dealing with information about the preparation of the gardens and importance of the consumption of healthy foods. At the end of the development of the project, it was possible to observe how satisfactory and relevant it was for each of the students, regardless of age, to help planting the seedlings, to observe the growth and development of each plant.

\section{Keywords: School garden; Healthy eating; Environmental education}




\section{Introdução}

Para fortalecer o vínculo positivo entre educação e saúde, deve-se desenvolver um ambiente saudável nas escolas, melhorando a educação e o potencial de aprendizagem e, ao mesmo tempo, promovendo a saúde (MINISTÉRIO DA SAÚDE, 2000). Do conjunto de temas que podem ser trabalhados no ambiente escolar, a alimentação tem um papel de destaque. Através desse tópico, crianças e adolescentes podem compartilhar suas experiências e refletir sobre as suas práticas alimentares, para modificá-las, caso seja necessário. Além disso, uma alimentação saudável é essencial para o bom desenvolvimento desses indivíduos, propiciando a melhoria no desenvolvimento físico, mental e socioambiental.

A falta de conhecimento dos discentes quanto ao meio ambiente e a escassez de ações desenvolvidas com relação à Educação Ambiental, Educação Alimentar e sustentabilidade são constatados nas escolas (PANTOJA, 2013). Por isso, despertar a consciência ambiental e implementar hábitos de vida saudáveis devem estar entre as preocupações sumárias das escolas, para formar adultos mais conscientes e preocupados com esses aspectos.

Buscando a realização desses objetivos, podem ser construídas hortas escolares, cujo espaço pode ser usado para estimular hábitos de alimentação saudáveis e proporcionar vivências ímpares no aprendizado e na vida dos indivíduos. Através da horta, pode-se contextualizar teoria e prática, o que traz benefícios importantes para a formação educacional dos discentes, proporciona uma excelente ferramenta para o ensino e a construção de opiniões críticas que estimulam a aprendizagem e a socialização, tanto dos alunos entre si, quanto destes com os demais agentes educacionais (MORGADO, 2008). Além disso, a horta altera sensivelmente a relação das pessoas com os ambientes naturais e urbanos, pois estimula a construção dos princípios de sustentabilidade e a valorização dos recursos naturais.

A horta torna-se uma ferramenta de ensino e aprendizagem de grande importância em escolas, principalmente por possibilitar abordar vários tópicos em um "laboratório vivo", que ao final de cada ciclo servirá de alimento para a própria comunidade escolar. Ainda, uma horta viva na escola pode inserir a comunidade no meio escolar.

Outro fator importante que justifica a implantação de hortas escolares é a necessidade de inserir os alunos do curso de Engenharia Agrícola em atividades de extensão, já que esses alunos quando egressos necessitarão muitas vezes repassar o seu conhecimento para os produtores rurais e comunidade em geral. O projeto é um aliado na construção de interdisciplinaridade no curso, vivenciada pelos alunos, aproxima a realidade dos conteúdos das disciplinas do curso, e também incentiva a transferência de conhecimentos para a comunidade.

Ainda, segundo Barbosa (2007), as hortas escolares constituem um meio para cumprir o papel fundamental da escola na promoção de estudos sobre as questões ambiental, alimentar e nutricional, a fim de aumentar a produção de alimentos saudáveis na região, que pode integrar a comunidade e interferir nos indicadores de desempenho dos alunos na escola.

Diante do exposto, descreve-se nesse artigo o desenvolvimento do projeto de extensão intitulado "Horta viva na escola", que teve como objetivo implantar horta em escolas que necessitem dessa ação, com a finalidade de desenvolver hábitos saudáveis e consciência socioambiental junto aos participantes.

\section{Material e métodos}

O projeto de extensão "Horta viva na escola" da Universidade Federal de Santa Maria - Campus Cachoeira do Sul (UFSM-CS) iniciou a implantação das hortas em escolas de Educação Infantil no primeiro semestre de 2017. Ainda nesse 
período, foi construída uma horta em uma escola de Ensino Médio. Após, no ano de 2018, foi implantada uma horta em uma escola de Ensino Fundamental.

O primeiro momento do projeto foi a escolha das escolas que receberiam a implantação da horta no ano de 2017. Entre as escolas selecionadas, foram definidas as seguintes instituições para receber as primeiras hortas do projeto: Escola Municipal de Educação Infantil Sol Criança, localizada no município de Santiago - RS, Colégio Totem, localizada em Cachoeira do Sul - RS (Educação Infantil) e Escola Estadual de Ensino Médio Ruy Barbosa, em Novo Cabrais - RS.

Em 2018, também foi escolhida a Escola Estadual de Ensino Fundamental Bairro Carvalho, localizada em Cachoeira do Sul - RS (Ensino Fundamental) para receber a atividade de implantação da horta.

A escolha das escolas foi realizada a partir de uma demanda e do interesse que cada instituição possuía em participar do projeto. Essas escolas se responsabilizaram em manter a horta de forma adequada com a colaboração dos acadêmicos do curso de Engenharia Agrícola da UFSM-CS, participantes do projeto.

A direção das escolas e os professores interessados em trabalhar com as diferentes temáticas na horta receberam todas as informações a respeito da finalidade do projeto "Horta viva na escola" e, posteriormente, a horta foi construída em locais com um solo adequado. Essa atividade de implantação das hortas ocorreu com o auxílio dos alunos do curso da Engenharia Agrícola da UFSM-CS, da comunidade, professores e funcionários das escolas.

A decisão de quais culturas seriam cultivadas na horta baseou-se na disponibilidade de sementes e mudas e na estação do ano adequada para implantação dessas culturas. Após a implantação da horta os professores de cada escola tiveram a liberdade de utilizar a horta da maneira que julgasse mais adequada para o processo de ensino e aprendizagem.

\section{Resultados e discussão}

\section{Escolas de Educação Infantil}

A horta desenvolvida na Escola Municipal de Educação Infantil Sol Criança recebeu solo rico em matéria orgânica, doado pelo Horto Florestal do município de Santiago - RS. Foram preparados canteiros utilizando pneus velhos doados pela comunidade e hortas no modelo vertical utilizando pallet de madeira também advindos de doação (Figura 1).

Figura 1 - Hortas das escolas de Educação Infantil. a) Horta de Escola Municipal de Educação Infantil Sol Criança em Santiago - RS. b) Horta no Colégio Totem em Cachoeira do Sul - RS.

(a)

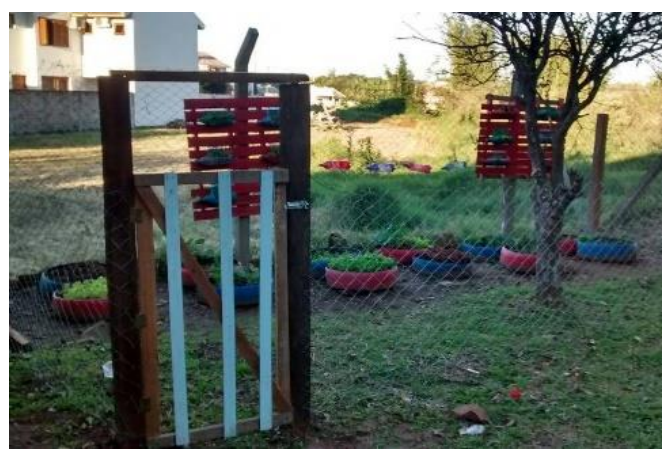

(b)

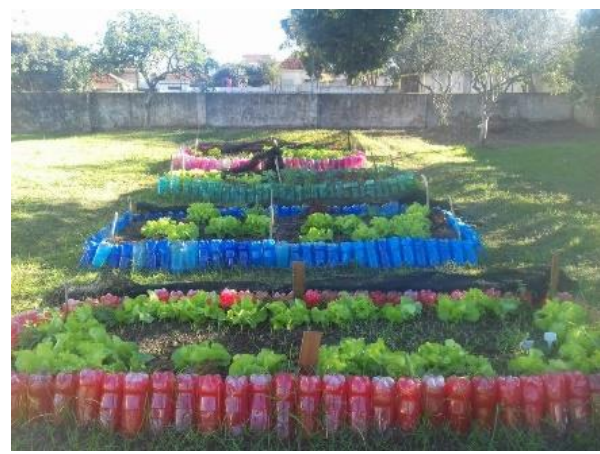
Fonte: Autores.

Em Cachoeira do Sul a horta foi implantada no Colégio Totem, uma escola particular com Educação Infantil, Ensino fundamental e Ensino Médio. No entanto, o espaço da horta foi utilizado pelas turmas de Educação Infantil e, nessa escola, os canteiros foram preparados utilizando garrafas pet que as famílias dos alunos foram responsáveis por levar até a escola. 
Utilizando restos de tinta guache, as garrafas pet foram coloridas e cada canteiro foi preparado com uma cor de garrafa pet. Dessa forma, cada turma se responsabilizou por cuidar de um canteiro. Foram quatro turmas envolvidas nas atividades com a horta, ou seja, na horta foram preparados quatro canteiros (Figura 1).

Nessas hortas foram cultivadas as seguintes culturas: alface, rabanete, repolho, cebola, salsa, couve, brócolis, cenoura, orégano, manjericão, manjerona, sálvia e alecrim, sendo que a semeadura e o plantio foram realizados com os alunos de forma que todos puderam participar da implantação da horta. Além disso, os alunos e a professora foram os responsáveis pelo manejo da horta e pela colheita das hortaliças (Figura 2).

Figura 2 - Plantio de hortaliças nas Hortas das escolas de Educação Infantil. a) Plantio das hortaliças na horta da Escola Municipal de Educação Infantil Sol Criança em Santiago - RS. b) Plantio das hortaliças na horta do Colégio Totem em Cachoeira do Sul - RS.

(a)

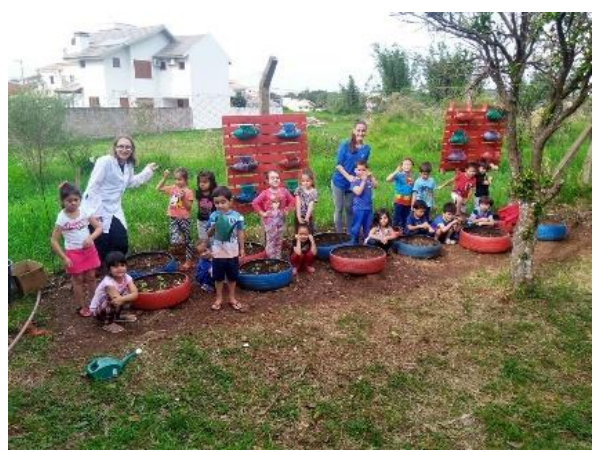

(b)

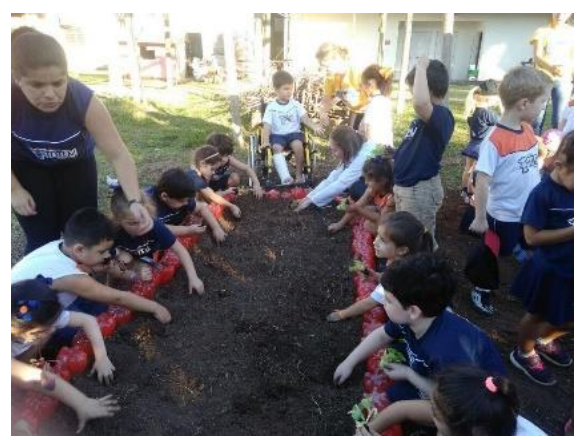

Fonte: Autores.

As hortaliças colhidas pelos alunos foram utilizadas na merenda escolar e foi realizada uma atividade extraclasse com as alfaces. Na atividade extraclasse, cada aluno levou para casa uma planta de alface e ficou na responsabilidade de preparar uma salada, degustar com a família e registrar a atividade com uma foto. Na Escola Municipal de Educação Infantil Sol Criança, juntamente com a foto, as famílias fizeram um relato da experiência vivida pelos alunos com relação ao projeto, que auxiliou na construção de uma cartilha, onde todas as atividades relacionadas à horta foram publicadas, que foi lançada na Feira do Livro do município de Santiago (Figura 3).

Figura 3 - Cartilha lançada na Feira do Livro do município de Santiago - RS. a) Capa do livro. b) Autógrafos dos alunos na cartilha lançada na Feira do Livro.

(a)

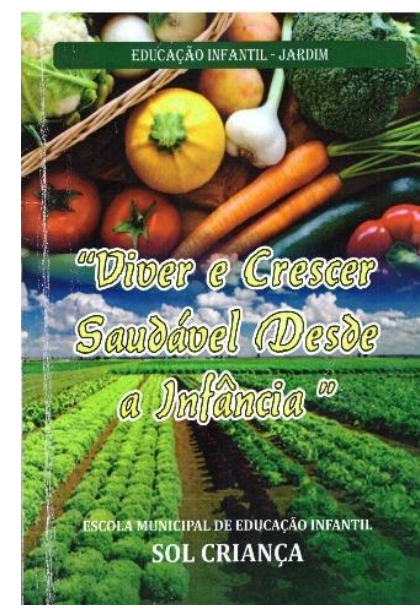

(b)

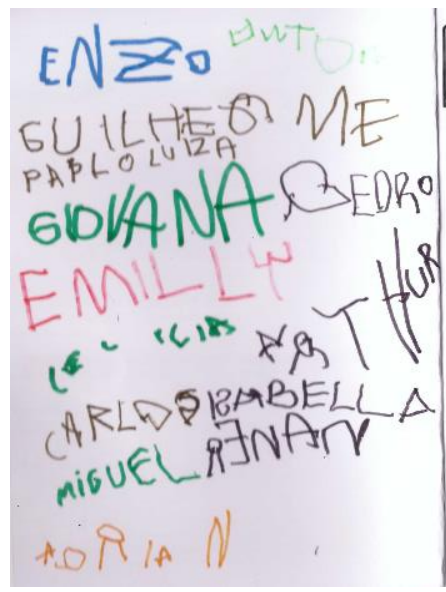

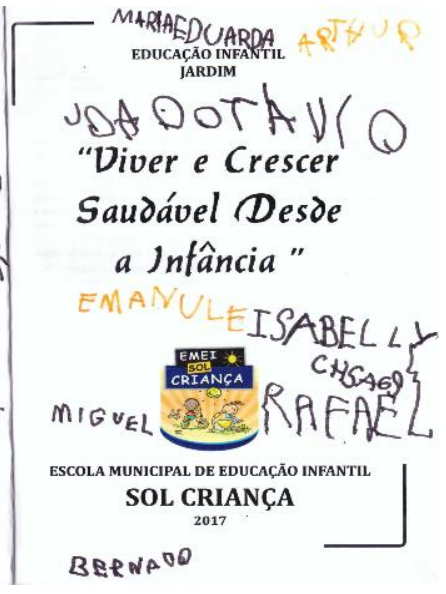




\section{Escola de Ensino Fundamental}

A horta na Escola Estadual de Ensino Fundamental Bairro Carvalho iniciou no primeiro semestre de 2018 com auxílio de alunos e funcionários da escola, além da comunidade.

Nessa escola, para fazer os canteiros, foram utilizadas telhas antigas oriundas da troca da cobertura da escola. Essa decisão foi tomada devido à reclamação da direção a respeito das telhas sem uso e que estariam atraindo animais peçonhentos para perto das salas de aula e quadra de esportes. Assim, foram preparados canteiros e as telhas utilizadas para demarcação dos mesmos (Figura 4).

Figura 4 - Horta na Escola de Ensino Fundamental Bairro Carvalho. a) Preparo dos canteiros b) Canteiros com hortaliças em crescimento.

(a)

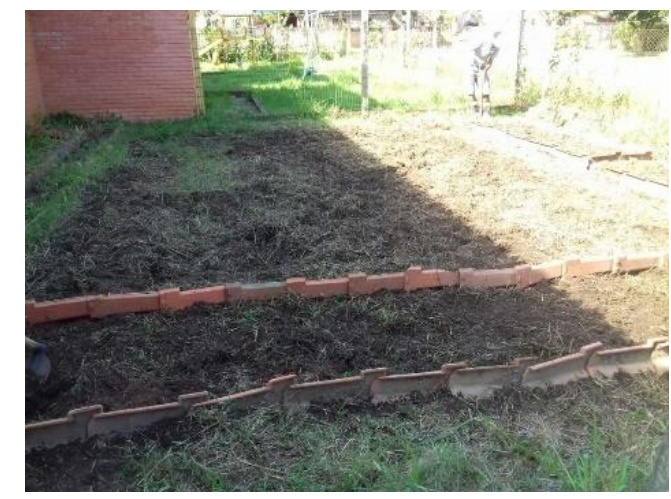

(b)

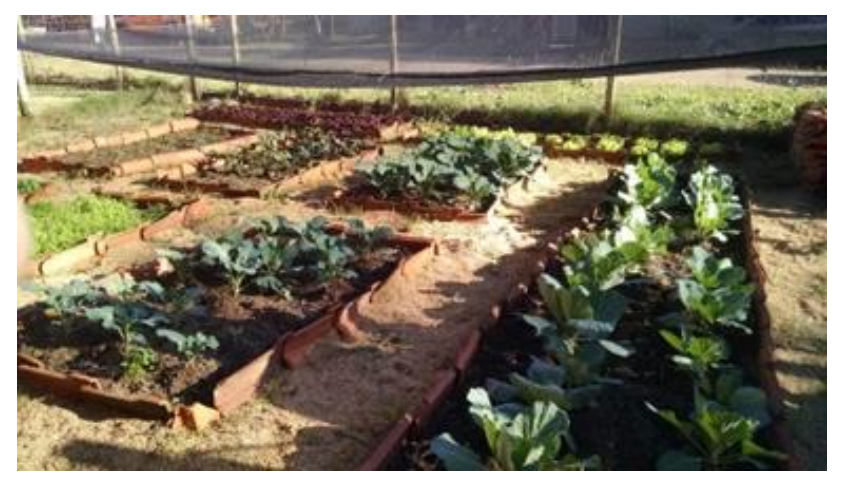

Fonte: Autores

$\mathrm{Na}$ horta da Escola Estadual de Ensino Fundamental Bairro Carvalho foram cultivadas as seguintes espécies: chuchu, rúcula, cebola, beterraba, cenoura, couve, brócolis, alface e repolho. Essas culturas foram utilizadas na merenda dos alunos.

O manejo da horta foi realizado por alunos do $5^{\circ}$ e $6^{\circ}$ ano juntamente com as funcionárias responsáveis pelo preparo da merenda escolar (Figura 5).

Figura 5 - Horta na Escola de Ensino Fundamental Bairro Carvalho. a) Manejo da horta realizado pelos alunos e funcionários da escola. b) Colheita de alface pelos alunos, para uso na merenda escolar.

(a)

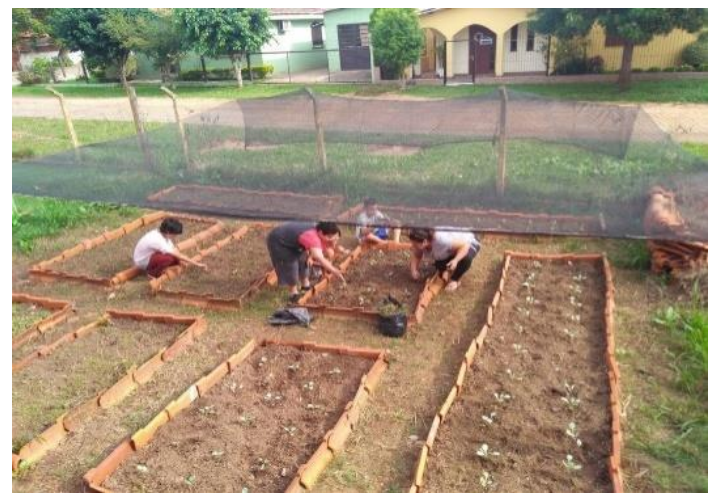

(b)

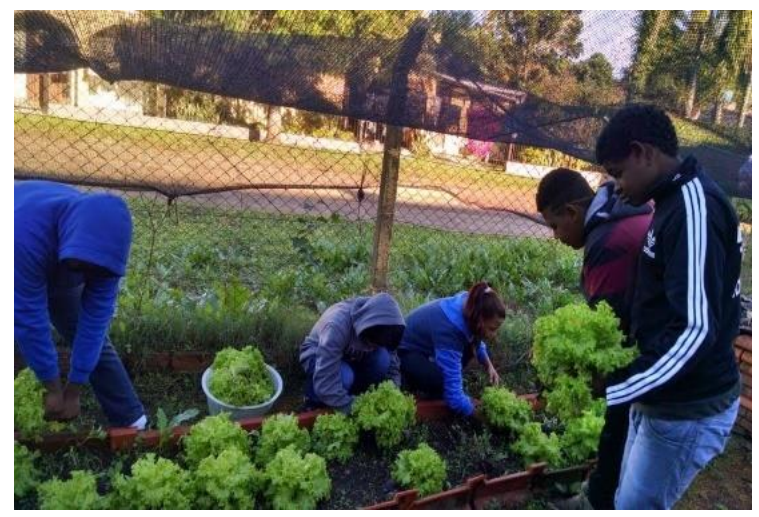

Fonte: Autores

A horta da Escola Estadual de Ensino Fundamental Bairro Carvalho servirá como laboratório vivo para atividades extra classe e para projetos interdisciplinares, além de aulas práticas de disciplinas voltadas a Ciências e Educação Ambiental, com o propósito de salientar e incentivar a alimentação saudável, sustentabilidade, dentre outras temas. 


\section{Escola de Ensino Médio}

A implantação da horta na Escola Estadual de Ensino Médio Ruy Barbosa iniciou no primeiro semestre de 2017. Com medidas de 11 metros de comprimento por 8 metros de largura, é a maior horta implantada pelo projeto de extensão "Horta viva na Escola".

Nessa horta os canteiros foram preparados no formato convencional e foi necessário o uso de trator e grade para o preparo do solo, pois a área disponível era proveniente de área com raízes de árvores e pedras. Para o preparo do solo foi necessário a ajuda da comunidade. Além disso, a horta foi cercada por voluntários da comunidade do entorno da escola (Figura $6)$.

Figura 6 - Horta na Escola Estadual de Ensino Médio Ruy Barbosa. a) Participantes do Projeto Horta viva na escola com trator emprestado por pessoa da comunidade para gradear a área da horta. b) Área da horta sendo cercada com auxílio da comunidade.

(a)

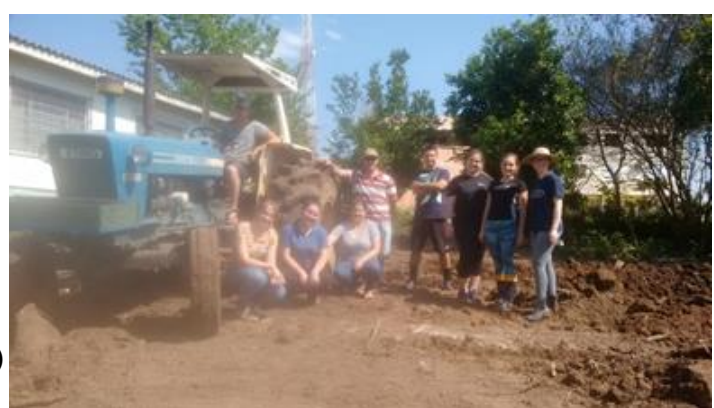

Fonte: Autores. (b)

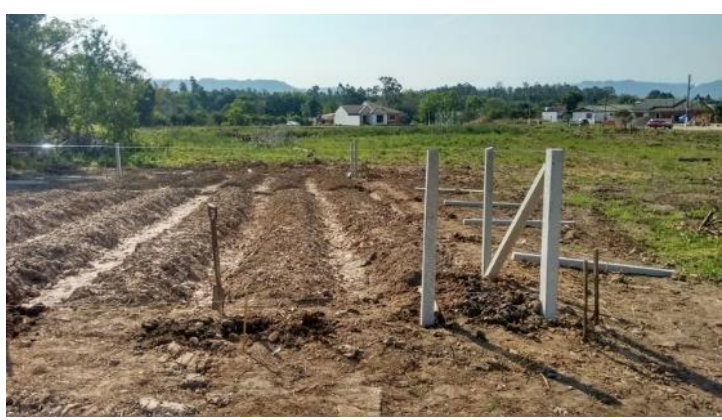

As espécies cultivadas na horta foram: alface, radite, rúcula. cebola, beterraba, repolho, couve, couve flor, tomate, cebolinha, salsa, morango, batata doce, mandioca, alecrim, manjerona, manjericão, abóbora, moranga, capim cidreira, funcho, mandioca, pimentão, rabanete, espinafre, roseiras e cravo-de-defunto. Foram cultivadas desde espécies de pequeno porte como a alface até espécies de maior porte como o milho pipoca e a mandioca (Figura 7).

Figura 7 - Horta na Escola Estadual de Ensino Médio Ruy Barbosa. a) Canteiros com culturas de menor porte (alface, cebolinha, feijão, dentre outras). b) Cateiro com culturas de maior porte (milho, milho pipoca e mandioca).

(a)

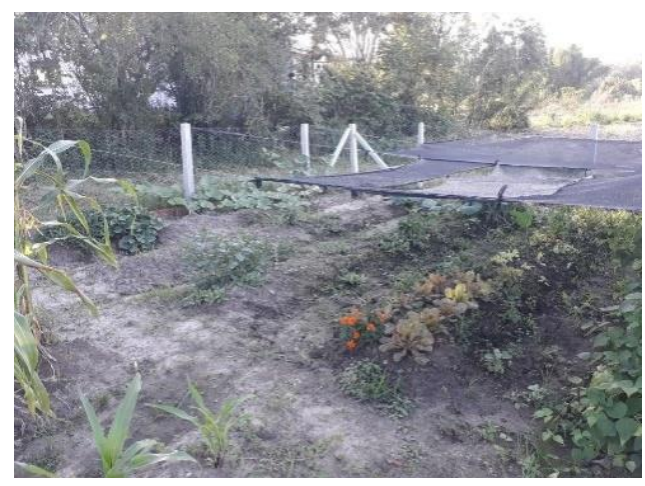

(b)

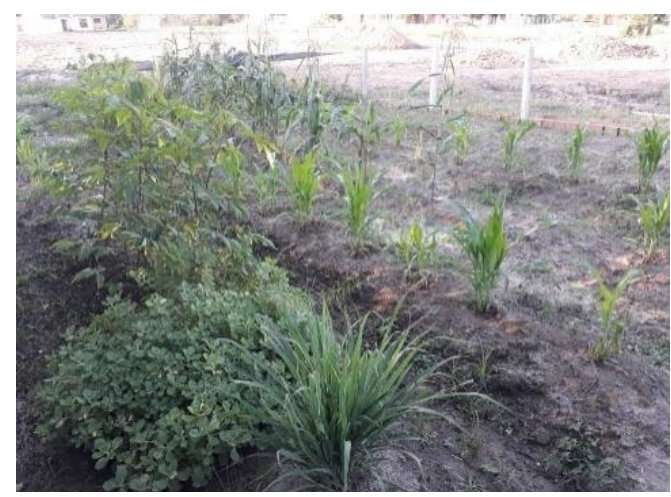


Nessa horta foi necessário realizar uma adubação, pois a área não estava em condições favoráveis para implantação das hortaliças logo após a realização do preparo do solo, visto que este solo não estava sendo utilizado pela escola durante um longo período. Essa adubação foi a base de esterco de aves e bovinos, proporcionando Maio $\mathrm{r}$ crescimento e produção das culturas da horta.

A produção da horta é utilizada na alimentação dos alunos que é disponibilizada pela escola durante o turno que os alunos se encontram na escola, além de ser utilizada na alimentação de professores e funcionários (Figura 8a). Ainda, a horta é utilizada pelos professores para atividades extra classe, aulas práticas e projetos interdisciplinares (Figura 8b).

Figura 8 - Horta na Escola Estadual de Ensino Médio Ruy Barbosa. a) Produtos oriundos de colheita na horta. b) Atividade extra classe realizada com o $2^{\circ}$ ano do Ensino Médio.

(a)

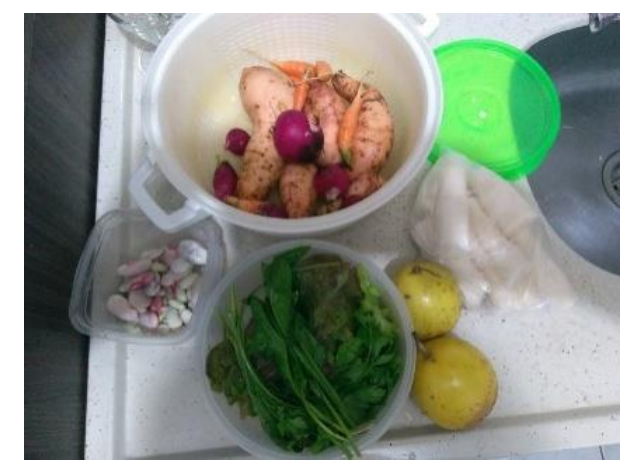

(b)

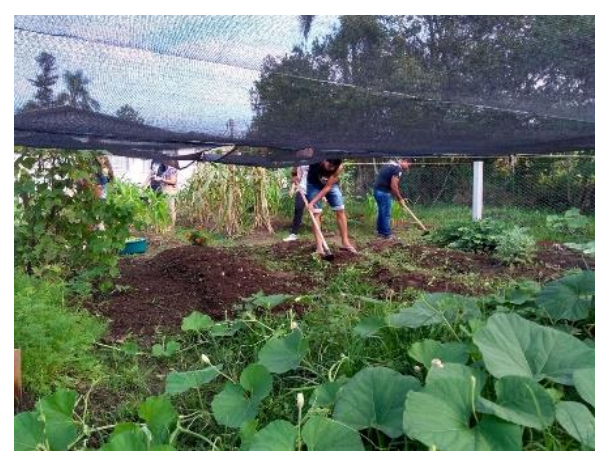

Fonte: Autores.

\section{Conclusões}

Com a implantação das hortas nas escolas foi possível observar o quanto é importante para os alunos de todos os níveis de ensino (Ensino Infantil, Ensino Fundamental e Ensino Médio), as atividades práticas que desenvolvem a criatividade, trabalho coletivo, aplicação de conhecimentos trabalhados nas disciplinas em sala de aula e também a conscientização sobre o meio ambiente, sustentabilidade e alimentação saudável.

Aos acadêmicos do curso de Engenharia Agrícola da UFSM-CS, o projeto "Horta viva na escola" proporcionou o contato com uma comunidade externa à comunidade acadêmica, permitindo compartilhar e aplicar os conhecimentos obtidos na Universidade.

A realização do projeto proporcionou aos participantes uma nova ideia de alimentação saudável e de sustentabilidade em pequenos espaços, como o caso de uma horta no quintal da escola, transformando um espaço ocioso da escola em uma horta viva com alimento disponível durante todo o ano.

Os resultados do projeto são alunos mais conscientes que levam para a vida ensinamentos ambientais, sociais e de sustentabilidade, amplificando a necessidade de uma mudança de postura necessária na sociedade com relação à natureza. 


\section{Referências}

BARBOSA, N. V. S. Caderno 1: A Horta Escolar como Parte do Currículo da Escola. Brasília, 2007.

MINISTÉRIO DA SAÚDE. Política nacional de alimentação e nutrição. Brasília, 2000.

MORGADO, F. S. A Horta Escolar na educação ambiental: experiência do projeto horta viva nas escolas municipais de Florianópolis, Revista Eletrônica de Extensão. 2008: (6) 1-10.

PANTOJA, T.F. et al. A importância da horta escolar no processo ensino aprendizagem de botânica em uma escola de Macapá, AP. Anais do $64^{\circ}$ Congresso Nacional de Botânica. Belo Horizonte, 2013. 